\title{
Modeling of the Hydration Shell of Uracil and Thymine
}

\author{
Oleg V. Shishkin ${ }^{1,2}$, Leonid Gorb ${ }^{2}$ and Jerzy Leszczynski ${ }^{2} *$ \\ ${ }^{1}$ Department of Alkali Halide Crystals, Institute for Single Crystals, National Academy of Sciences of \\ Ukraine, 60 Lenina Avenue., Kharkiv 310001, Ukraine \\ ${ }^{2}$ Computational Center for Molecular Structure and Interactions, Department of Chemistry, Jackson \\ State University, P.O. Box 17910, 1325 Lynch Street, Jackson, MS 39217, USA \\ E-mail: jerzy@tiger.jsums.edu
}

*Author to whom correspondence should be addressed.

Received: 4 January 2000 / Accepted: 30 March 2000 / Published: 4 March 2000

\begin{abstract}
The molecular geometry of complexes of uracil and thymine with 11 water molecules was calculated using the density functional theory with the B3LYP functional. The standard 6-31G(d) basis set has been employed. It was found that the arrangement of water molecules forming a locked chain around the nucleobases significantly differs for uracil and thymine. The presence of a methyl group in thymine results in strong non-planarity of the hydrated shell. The existence of C-H...O hydrogen bonds between the water molecules and the hydrophobic part of the nucleobases is established. Interactions with water molecules cause some changes in the geometry of uracil and thymine which can be explained by the contribution of a zwitter-ionic dihydroxy resonance form into the total structure of the molecules.
\end{abstract}

Keywords: Uracil, Thymine, Hydration, Molecular structure, Hydrogen bonds, Density functional theory.

\section{Introduction}

Since Franklin and Gosling [1] examined the first fibers of DNA it has been known that DNA occurs in vivo in the hydrated form. Numerous experimental studies using different methods [2,3] have led to the conclusion that DNA is heavily hydrated. The hydration layer is known to play a crucial role

(C) 2000 by Molecular Diversity Preservation International (MDPI, http://www.mdpi.org/) 
in promoting nucleic acid base stacking and helix stabilization [4,5]. So, it is not surprising that interactions of nucleic acid bases with water molecules play a special role in determining the threedimensional structure of these types of biopolymers [5,6]. Although all of the available modern experimental techniques are involved in the investigations of DNA structure and function, in many cases the experiments are still unable to provide direct evidence for the investigated phenomena. Therefore, computational methods are useful and powerful tools which are able to answer many questions especially related to detailed mechanism of intermolecular interactions with the participation of DNA and its constituents.

Hydration of nucleobases was a subject of numerous theoretical studies using Monte-Carlo [7], molecular dynamics [8], and quantum-chemical approaches within the continuum solvent model (see for example 9, 10,11, 12,13). These investigations were focused mainly on the estimation of the solvation free energy since this value may be directly compared with the experimental data.

However, all these methods are not able to describe reliably the details of the interactions between nucleobases and water molecules because of their limitations. Such information may by obtained only within the supermolecular approach using high level ab initio methods. Recent calculations of the hydrated complexes of uracil [14,15], thymine [16], cytosine [16-18], guanine [19], and adenine [20] performed at the HF and MP2 levels of theory reveal that the geometrical parameters of DNA bases may be extremely sensitive to the direct influence of water molecules. Moreover, a theoretical investigation of the complex of cytosine with 14 water molecules [21] has led to the conclusion that the molecular structure of this molecule cannot be described by conventional chemical formula.

Some contradictions exist concerning the structure of the first solvation shell of uracil and thymine. Chahinian et al. [22], on the basis of an NMR study, conclude that the first solvation shell of uracil includes only three water molecules. This experimental observation has been done in the mixture of DMSO and water. However, theoretical studies of mono-, di-, and three-hydrated complexes of uracil and thymine [14-16,23] demonstrate the considerably large number of binding sites for water molecules. This implies that generally more than three water molecules could play a crucial role during the hydration of nucleobases in water solution.

All previous investigations of the hydrated complexes of uracil and thymine include only up to three water molecules. Therefore, there is considerable ambiguity in the extrapolation of these theoretical data to solutions of nucleobases in water. In the present paper, we report the results of calculations of complexes of uracil and thymine with 11 water molecules that form a locking chain around nucleobases.

\section{Method of Calculation}

To build a hydration shell around the cytosine molecule we have used the modified scheme of monosolvation which originates in the early work of Pullman [24].

The procedure for building uracil and thymine complexes with water molecules is as follows. The 
structure of all possible monohydrated complexes was fully optimized, and the most stable complex is revealed. Then a second water molecule is added, and the hydrated complex having the lowest energy is found in the same way. Such a procedure is repeated until 11 water molecules are arranged around the nucleobase in order to lock the chain.

It is obvious that the potential surface of the polyhydrated molecules has a number of minima having a different orientation of water molecules and close energy values. We assume that a change in orientation should not drastically effect the geometry of uracil and thymine. This is why we did not study the influence of a different orientation of water molecules. We also believe that the rotation of any water molecules will destroy the net of hydrogen bonds and will result in a structure with higher energy than the obtained structure.

All calculations were carried out using the density functional theory with Becke's three-parameter exchange functional [25] along with the Lee-Yang-Parr non-local correlation functional (B3LYP) [26,27] which is reliable in describing hydrogen bonding phenomena [28,29,30]. The standard 6$31 \mathrm{G}(\mathrm{d})$ basis set was used. All structures were fully optimized by analytic gradient techniques. The characteristics of the calculated local minima structures were verified by establishing that the matrices of the energy second derivatives (Hessians) do not have negative eigenvalues.

Atomic charges were calculated using the Mulliken and natural bond orbitals (NBO) population analysis [31]. The topological characteristics of electron density distribution were obtained following Bader's "Atoms in Molecules" approach [32] using the wavefunction obtained at the same level of theory. All calculations were performed using the Gaussian94 program package [33].

\section{Results and Discussion}

The optimized structures of complexes of uracil and thymine with 11 water molecules are presented in Fig. 1 and 2. As is evident, all water molecules can be divided into two groups. The first group includes $\mathrm{H}_{2} \mathrm{O}$ molecules which form hydrogen bonds with the nucleobase (W1-W6 for both uracil and thymine). The remaining water molecules are located around the hydrophobic part of the nucleobase and do not interact with it by means of conventional H-bonds.

The results of the calculations reveal that six water molecules are arranged around the hydrophilic part of both uracil and thymine. Every $\mathrm{H}_{2} \mathrm{O}$ molecule forms only one hydrogen bond with the nucleobase in contrast to the model proposed by Chahinian et al. [22]. The pattern of hydrogen bonds around the hydrophilic part of uracil and thymine is very similar (Fig. 1 and 2; Table 1).

It is well known that the energy of the hydrogen bond depends on the Y...H distance and the X$\mathrm{H}$... $\mathrm{Y}$ angle (where $\mathrm{X}$ is a hydrogen donor and $\mathrm{Y}$ is a hydrogen accepting atom). Based on the $\mathrm{Y}$...H distance, all hydrogen bonds can be divided into strong (Y...H <1.6 $)$ ), medium (Y...H 1.6-1.9 $)$ ), and weak $(Y . . . \mathrm{H}>1.9 \AA$ A $)$ [34]. Based on this criteria H-bonds in the complex under study should be assigned as medium (see Table 1). The energy of this type of hydrogen bond reveals a rather small dependence on the value of the $\mathrm{Y} . . . \mathrm{H}-\mathrm{X}$ angle in the range $150-180^{\circ}$ [35]. Therefore, qualitatively, the energy of the H-bonds in the studied case may be estimated based only on the Y...H distances. 
Table 1. Geometry of hydrogen bonds in complexes of uracil and thymine with 11 water molecules.

\begin{tabular}{|c|c|c|c|c|}
\hline \multirow[b]{2}{*}{$\mathrm{X}-\mathrm{H} . . . \mathrm{Y}$} & \multicolumn{2}{|c|}{ Uracil } & \multirow[b]{2}{*}{$\rho, \mathrm{e} / \mathrm{au}^{3}$} & \multirow[b]{2}{*}{$\nabla^{2} \rho, \mathrm{e} / \mathrm{au}^{5}$} \\
\hline & $\begin{array}{r}\text { H...Y } \\
\text { distance, }\end{array}$ & $\begin{array}{c}\mathrm{X}-\mathrm{H} . . . \mathrm{Y} \\
\text { angle, deg. }\end{array}$ & & \\
\hline \multicolumn{5}{|c|}{ Uracil-water } \\
\hline N(1)-H...O(W1) & 1.748 & 173.1 & 0.045 & 0.127 \\
\hline O(W2)-H...O(7) & 1.828 & 171.3 & 0.034 & 0.105 \\
\hline $\mathrm{O}(\mathrm{W} 3)-\mathrm{H} . . . \mathrm{O}(7)$ & 1.881 & 169.6 & 0.030 & 0.094 \\
\hline N(3)-H...O(W4) & 1.645 & 178.3 & 0.057 & 0.153 \\
\hline $\mathrm{O}(\mathrm{W} 5)-\mathrm{H} \ldots \mathrm{O}(8)$ & 1.851 & 172.0 & 0.032 & 0.100 \\
\hline O(W6)-H...O(8) & 1.850 & 171.2 & 0.034 & 0.098 \\
\hline C(6)-H...O(W9) & - & - & - & - \\
\hline C(9)-H...O(W6) & - & - & - & - \\
\hline C(5)-H...O(W7) & 2.489 & 149.1 & 0.010 & 0.035 \\
\hline C(6)-H...O(W6) & 2.185 & 138.2 & 0.020 & 0.056 \\
\hline \multicolumn{5}{|c|}{ Water - Water } \\
\hline $\mathrm{O}(\mathrm{W} 1)-\mathrm{H} \ldots \mathrm{O}(\mathrm{W} 2)$ & 1.729 & 158.6 & 0.046 & 0.133 \\
\hline O(W4)-H...O(W3) & 1.834 & 154.0 & 0.037 & 0.106 \\
\hline $\mathrm{O}(\mathrm{W} 4)-\mathrm{H} . . . \mathrm{O}(\mathrm{W} 5)$ & 1.814 & 155.4 & 0.039 & 0.111 \\
\hline O(W7)-H...O(W6) & 1.823 & 172.0 & 0.036 & 0.105 \\
\hline $\mathrm{O}(\mathrm{W} 8)-\mathrm{H} . . . \mathrm{O}(\mathrm{W} 7)$ & 1.927 & 172.5 & 0.029 & 0.083 \\
\hline O(W8)-H...O(W9) & 2.018 & 151.3 & 0.025 & 0.072 \\
\hline O(W9)-H...O(W10) & 1.916 & 149.9 & 0.030 & 0.087 \\
\hline $\mathrm{O}(\mathrm{W} 10)-\mathrm{H} \ldots \mathrm{O}(\mathrm{W} 11)$ & 1.725 & 151.6 & 0.048 & 0.135 \\
\hline O(W11)-H...O(W1) & 1.942 & 146.0 & 0.029 & 0.084 \\
\hline $\mathrm{O}(\mathrm{W} 7)-\mathrm{H} . . . \mathrm{O}(\mathrm{W} 5)$ & - & - & - & - \\
\hline $\mathrm{O}(\mathrm{W} 1)-\mathrm{H} \ldots \mathrm{O}(\mathrm{W} 10)$ & - & - & - & - \\
\hline \multicolumn{5}{|c|}{ Thymine } \\
\hline X-H...Y & H...Y distance, & $\begin{array}{c}\text { X-H...Y } \\
\text { angle, deg. }\end{array}$ & $\rho, \mathrm{e} / \mathrm{au}^{3}$ & $\nabla^{2} \rho$, e/au ${ }^{5}$ \\
\hline \multicolumn{5}{|c|}{ Thymine-water } \\
\hline N(1)-H...O(W1) & 1.771 & 176.8 & 0.042 & 0.119 \\
\hline $\mathrm{O}(\mathrm{W} 2)-\mathrm{H} \ldots \mathrm{O}(7)$ & 1.792 & 172.1 & 0.037 & 0.116 \\
\hline O(W3)-H...O(7) & 1.843 & 170.3 & 0.033 & 0.103 \\
\hline N(3)-H...O(W4) & 1.710 & 176.3 & 0.049 & 0.133 \\
\hline O(W5)-H...O(8) & 1.779 & 165.8 & 0.039 & 0.119 \\
\hline O(W6)-H...O(8) & 1.918 & 158.6 & 0.034 & 0.109 \\
\hline C(6)-H...O(W9) & 2.381 & 108.9 & 0.014 & 0.052 \\
\hline C(9)-H...O(W6) & 2.674 & 137.8 & 0.007 & 0.027 \\
\hline C(5)-H...O(W7) & - & - & - & - \\
\hline C(6)-H...O(W6) & - & - & - & - \\
\hline \multicolumn{5}{|c|}{ Water - Water } \\
\hline $\mathrm{O}(\mathrm{W} 1)-\mathrm{H} . . . \mathrm{O}(\mathrm{W} 2)$ & 1.716 & 161.9 & 0.047 & 0.137 \\
\hline O(W4)-H...O(W3) & 1.805 & 159.1 & 0.039 & 0.112 \\
\hline O(W4)-H...O(W5) & 1.923 & 146.5 & 0.029 & 0.089 \\
\hline O(W7)-H...O(W6) & 1.899 & 152.1 & 0.031 & 0.090 \\
\hline O(W8)-H...O(W7) & 1.732 & 170.8 & 0.045 & 0.129 \\
\hline O(W8)-H...O(W9) & 1.898 & 171.8 & 0.032 & 0.088 \\
\hline O(W9)-H...O(W10) & 1.979 & 163.3 & 0.025 & 0.076 \\
\hline O(W10)-H...O(W11) & 1.794 & 153.7 & 0.040 & 0.114 \\
\hline O(W11)-H...O(W1) & 1.856 & 150.6 & 0.034 & 0.100 \\
\hline O(W7)-H...O(W5) & 1.827 & 156.1 & 0.031 & 0.086 \\
\hline $\mathrm{O}(\mathrm{W} 1)-\mathrm{H} \ldots \mathrm{O}(\mathrm{W} 10)$ & 1.869 & 149.1 & 0.033 & 0.098 \\
\hline
\end{tabular}




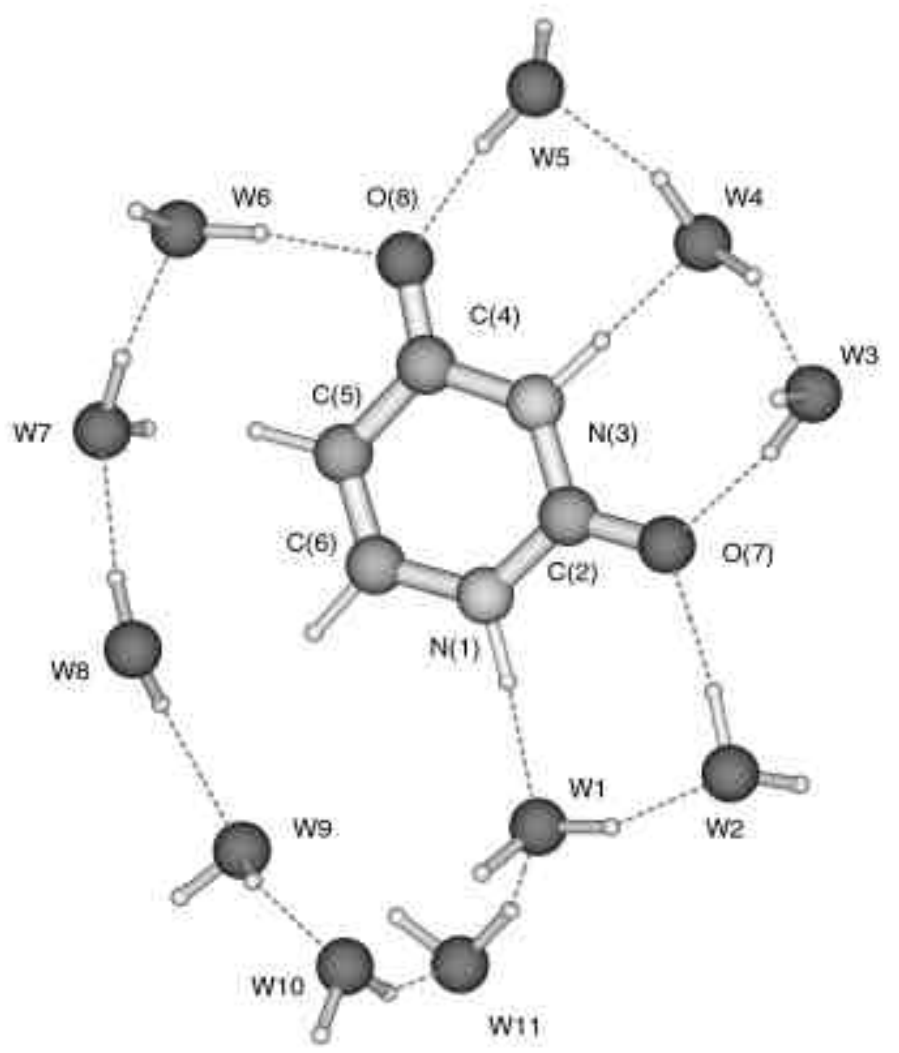

Figure 1. Structure of the complex of uracil with 11 water molecules. The full color 3D structure is stored in the same folder as this paper as the file i1020017-1.pdb.

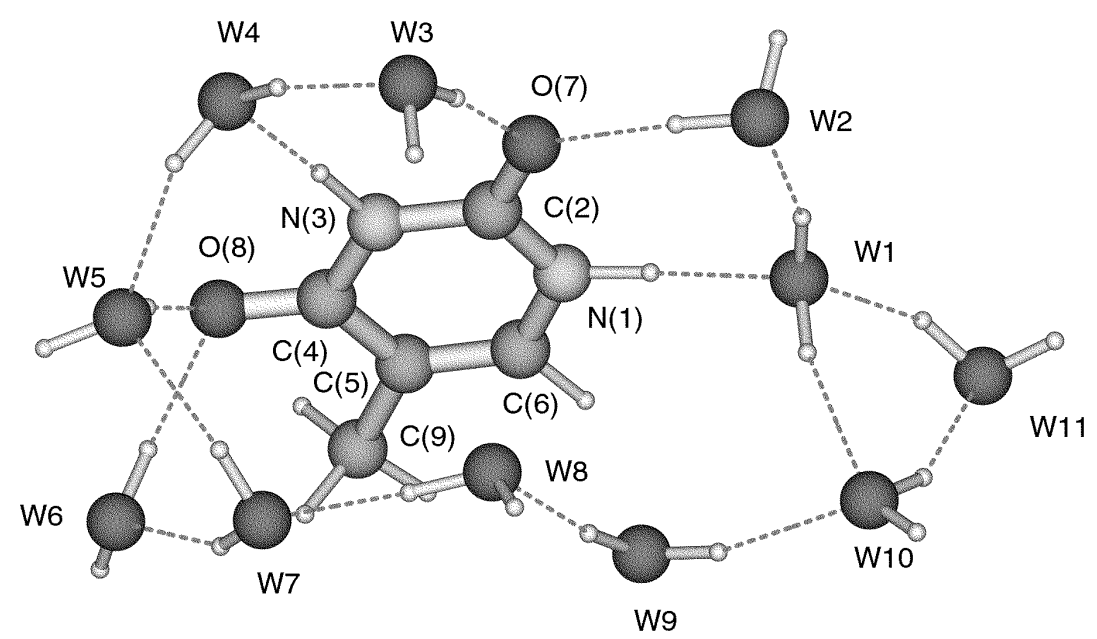

Figure 2. Structure of the complex of thymine with 11 water molecules. The full color 3D structure is stored in the same folder as this paper as the file i1020017-2.pdb. 
An alternative approach to an analysis of the hydrogen bond energy is provided by the topological characteristics of electron density distribution [29]. It was demonstrated that the value of electron density and its Laplacian in the bond critical point $(3,-1)$ correlates with the bond energy [32]. Therefore, a comparison of the H-bond strength may be also carried out based on these values.

An analysis of the geometrical characteristics of $\mathrm{H}$-bonds and the values of Laplacian of electron density allow us to conclude that, in general, hydrogen bonds between water molecules and nucleobases have similar characteristics (Table 1) for uracil and thymine complexes. The strength of the $\mathrm{H}$ bonds depends also on the interacting part of the nucleobase. The NH groups form stronger hydrogen bonds compared to the carbonyl oxygens.

The most striking difference between the hydration shell of uracil and thymine is revealed for water molecules arranged around the hydrophobic fragment of nucleobases. This part of the shell contains five $\mathrm{H}_{2} \mathrm{O}$ molecules for both complexes under study (Fig.1 and 2). However, their arrangement is very different. In the case of the complex of uracil, the water molecules are located near the mean plane of the pyrimidine ring (Fig 3a). Replacement of the hydrogen atom in uracil by the methyl group in thymine results in an extremely non-planar arrangement of the water shell around the hydrophobic part of the nucleobase (Fig 3b). The W7-W11 molecules in the complex of thymine are located above the mean plane of the pyrimidine ring. This also causes some deviation from planarity of hydrogen bonds with the participation of the $\mathrm{O}(8)$ atom in thymine as compared with uracil. The $\mathrm{N}(3)-\mathrm{C}(4)-\mathrm{O}(8) \ldots \mathrm{H}-$ $\mathrm{O}(\mathrm{W} 5)$ and $\mathrm{C}(5)-\mathrm{C}(4)-\mathrm{O}(8) \ldots \mathrm{H}-\mathrm{O}(\mathrm{W} 6)$ torsion angles are $-7.5^{\circ},-23.3^{\circ}$ and $43.7^{\circ},-40.3^{\circ}$ for uracil and thymine, respectively. Some differences are observed also in the pattern of the H-bonds between the complexes under study. In the case of hydrated uracil, the W7-W11 molecules are consequently connected to each other (Fig.1) while in the complex thymine $11 \mathrm{H}_{2} \mathrm{O}$, molecules $\mathrm{W} 7$ and $\mathrm{W} 11$ play a role a bridge between molecules W5, W6 and W1, W10, respectively (Fig. 2).

In general, hydrogen bonds between water molecules are weaker compared to water-nucleobase interactions (Table 1). This especially concerns interactions between $\mathrm{H}_{2} \mathrm{O}$ molecules located around the hydrophobic part of the nucleobase (except for the W10...W11 bond for hydrated uracil and thymine and the W7...W8 bond for thymine) (Table 1).

The characteristics of interactions of water molecules with the hydrophobic part of nucleobases are the subject of special interest. During the last decade, the existence of weak C-H...O hydrogen bonds in many crystals [36] and biological structures [37]was established. These bonds are characterized by longer O...H distances (2.2-2.6 $\mathrm{A}$ ) at the same range of values of the C-H...O angle as compared with conventional hydrogen bonds. Such interactions provide additional contribution to the total binding energy. Molecular dynamics studies have shown that C-H...O interactions are possible between the C$\mathrm{H}$ groups of nucleic acid bases and the oxygen atoms of water molecules [38]. An analysis of the structure of the complex under study reveals distances between the hydrogen atoms in the hydrophobic part of uracil and thymine and the nearest water molecules (Table 1). It allows one to assume the existence of weak C-H...O hydrogen bonds. However, on the basis of analysis of the NMR data for hydrated uracil, Chahinian et al. [22] concluded that water is kept far away from the $\mathrm{C}(5)-\mathrm{C}(6)$ double bond, and therefore formation of the C-H...O hydrogen bonds is impossible. 

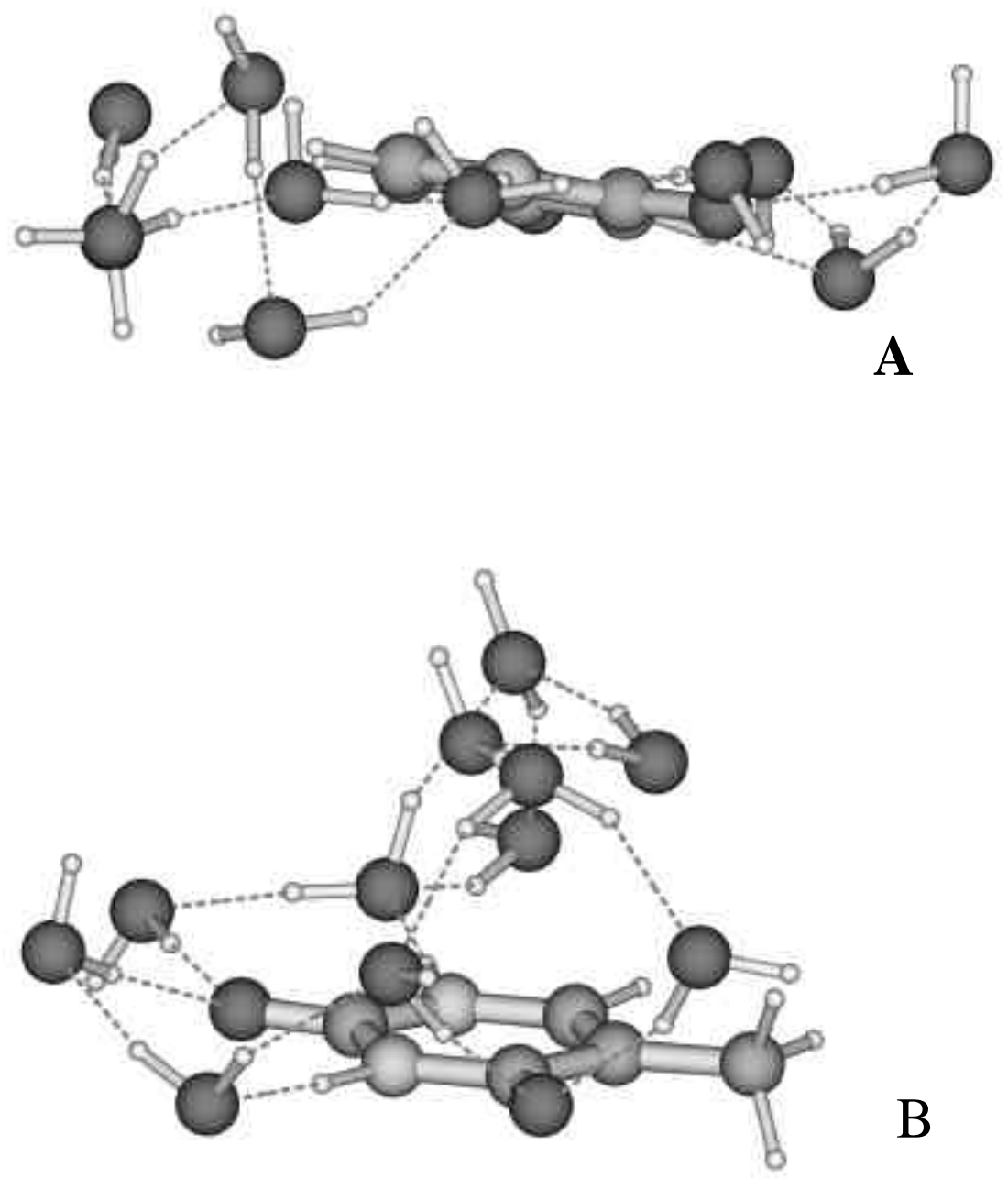

Figure 3. Arrangement of the water molecules with respect to the mean plane of the nucleobases:

a) uracil and b) thymine.

This disagreement may be unambiguously solved by an analysis of the electron density distribution topology. The existence of the $(3,-1)$ critical point indicates the formation of chemical bonds independently of its nature [32]. An analysis of the electron density distribution in the complexes under study reveals the presence of such critical points on the $\mathrm{C}(5)-\mathrm{H}$...O(W7) and $\mathrm{C}(6)-\mathrm{H}$...O(W6) lines for uracil and on the $\mathrm{C}(6)-\mathrm{H} . . . \mathrm{O}(\mathrm{W} 9)$ and $\mathrm{C}(9)-\mathrm{H} . . . \mathrm{O}(\mathrm{W} 6)$ lines for thymine. Thus, this finding confirms the existence of the C-H...O bonds between the hydrophobic part of uracil and thymine and the water molecules. The values of Laplacian of the electron density demonstrate that these H-bonds are very weak (Table 1).

A comparison of the geometry of isolated and hydrated uracil and thymine reveals that the interaction with water molecules noticeably influences the molecular structure of nucleobases under consideration (Table 2). 
Table 2. Molecular geometry ( $\mathrm{A}$, deg.) of isolated and hydrated uracil and thymine.

\begin{tabular}{ccccc}
\hline Geometrical & \multicolumn{2}{c}{ Uracil } & \multicolumn{2}{c}{ Thymine } \\
\cline { 2 - 5 } Parameters & Isolated & Hydrated & Isolated & Hydrated \\
\hline $\mathrm{N}(1)-\mathrm{C}(2)$ & 1.396 & 1.373 & 1.390 & 1.366 \\
$\mathrm{C}(2)-\mathrm{N}(3)$ & 1.385 & 1.373 & 1.386 & 1.372 \\
$\mathrm{~N}(3)-\mathrm{C}(4)$ & 1.414 & 1.392 & 1.408 & 1.387 \\
$\mathrm{C}(4)-\mathrm{C}(5)$ & 1.460 & 1.437 & 1.468 & 1.444 \\
$\mathrm{C}(5)-\mathrm{C}(6)$ & 1.350 & 1.354 & 1.352 & 1.360 \\
$\mathrm{C}(6)-\mathrm{N}(1)$ & 1.376 & 1.367 & 1.380 & 1.367 \\
$\mathrm{C}(2)-\mathrm{O}(7)$ & 1.217 & 1.247 & 1.218 & 1.247 \\
$\mathrm{C}(4)-\mathrm{O}(8)$ & 1.219 & 1.250 & 1.222 & 1.253 \\
$\mathrm{C}(5)-\mathrm{C}(9)$ & - & - & 1.501 & 1.503 \\
$\mathrm{~N}(1)-\mathrm{C}(2)-\mathrm{N}(3)$ & 112.7 & 115.9 & 112.4 & 115.3 \\
$\mathrm{C}(2)-\mathrm{N}(3)-\mathrm{C}(4)$ & 128.4 & 125.2 & 128.3 & 125.3 \\
$\mathrm{~N}(3)-\mathrm{C}(4)-\mathrm{C}(5)$ & 113.3 & 115.7 & 114.5 & 116.7 \\
$\mathrm{C}(4)-\mathrm{C}(5)-\mathrm{C}(6)$ & 120.0 & 119.4 & 118.2 & 117.3 \\
$\mathrm{C}(5)-\mathrm{C}(6)-\mathrm{N}(1)$ & 121.9 & 121.5 & 122.7 & 122.5 \\
$\mathrm{C}(6)-\mathrm{N}(1)-\mathrm{C}(2)$ & 123.7 & 122.4 & 123.9 & 122.6 \\
$\mathrm{~N}(1)-\mathrm{C}(2)-\mathrm{O}(7)$ & 122.8 & 121.8 & 123.2 & 122.5 \\
$\mathrm{~N}(3)-\mathrm{C}(4)-\mathrm{O}(8)$ & 120.4 & 120.1 & 120.4 & 119.3 \\
$\mathrm{C}(6)-\mathrm{C}(5)-\mathrm{C}(9)$ & - & - & 124.1 & 123.0 \\
$\mathrm{~N}(1)-\mathrm{C}(2)-\mathrm{N}(3)-\mathrm{C}(4)$ & 0 & 2.1 & 0 & 5.7 \\
\hline
\end{tabular}

Table 3. Atomic charges derived from Mulliken and natural bond orbital population analyses.

\begin{tabular}{ccccccccc}
\hline \multicolumn{4}{c}{ Uracil } & \multicolumn{5}{c}{ Thymine } \\
\hline Atom & \multicolumn{3}{c}{ Mulliken charges } & \multicolumn{2}{c}{ NBO charges } & \multicolumn{2}{c}{ Mulliken charges } & \multicolumn{2}{c}{ NBO charges } \\
\hline & Isolated & Hydrated & isolated & Hydrated & isolated & Hydrated & Isolated & Hydrated \\
\hline $\mathrm{N}(1)$ & -0.64 & -0.66 & -0.64 & -0.62 & -0.64 & -0.64 & -0.63 & -0.60 \\
$\mathrm{C}(2)$ & 0.77 & 0.80 & 0.82 & 0.84 & 0.76 & 0.76 & 0.82 & 0.86 \\
$\mathrm{~N}(3)$ & -0.69 & -0.72 & -0.68 & -0.66 & -0.69 & -0.69 & -0.68 & -0.65 \\
$\mathrm{C}(4)$ & 0.62 & 0.66 & 0.65 & 0.67 & 0.59 & 0.59 & 0.66 & 0.68 \\
$\mathrm{C}(5)$ & -0.25 & -0.27 & -0.39 & -0.40 & 0.05 & 0.04 & -0.18 & -0.19 \\
$\mathrm{C}(6)$ & 0.11 & 0.10 & 0.03 & 0.07 & 0.05 & 0.04 & 0.03 & 0.08 \\
$\mathrm{C}(9)$ & - & - & - & - & -0.51 & -0.53 & -0.68 & -0.68 \\
$\mathrm{O}(7)$ & -0.50 & -0.60 & -0.62 & -0.72 & -0.50 & -0.56 & -0.62 & -0.73 \\
$\mathrm{O}(8)$ & -0.50 & -0.60 & -0.59 & -0.70 & -0.50 & -0.56 & -0.59 & -0.71 \\
\hline
\end{tabular}




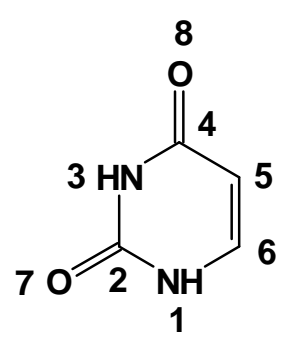

A

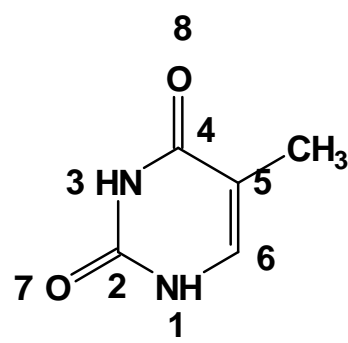

A<smiles>[O-]c1cc[nH+]c(O)n1</smiles>

B<smiles></smiles>

B

Formation of hydrogen bonds with the participation of the carbonyl groups results in the elongation (up to $0.03 \AA$ ) of the $\mathrm{C}=\mathrm{O}$ double bonds. This is also accompanied by a shortening of the bonds within the pyrimidine ring (Table 2) except for the $\mathrm{C}(5)=\mathrm{C}(6)$ double bond. Deformation of the nucleobases due to the interaction with water may be interpreted as a contribution of resonance form $\mathbf{B}$ into the total structure of the molecules. This assumption is also supported by changes in the endocyclic bond angles within the pyrimidine ring (Table 2). Their values are closer to $120.0^{\circ}$ in the hydrated nucleobases compared with the isolated ones. It should be noted that changes in the geometry of uracil and thymine in the complexes under study are significantly larger compared with the data for the mono, diand, three-hydrates of these molecules [14-16,23] and the results of the calculations using continuum models [9]. However, the deformation of nucleobases is much smaller compared to hydrated cytosine [21].

The interaction of uracil and thymine with water results in some out-of-plane deformation of the pyrimidine ring (Table 2). Earlier, it was demonstrated that the heterocycle in these nucleobases possesses high conformational flexibility [39]. Transition from a planar equilibrium to a sofa conformation with the $\mathrm{N}(1)-\mathrm{C}(2)-\mathrm{N}(3)-\mathrm{C}(4)$ torsion angle $\pm 20^{\circ}$ causes an energy increase of less than $1 \mathrm{kcal} / \mathrm{mol}$ [40]. This value is considerably smaller than the energy of the hydrogen bonds. However, only slight deformation of the pyrimidine ring is observed in the complexes under study (Table 2). The strongly non-planar structure of the hydrated shell in the complex of thymine results in a larger value of the $\mathrm{N}(1)-\mathrm{C}(2)-\mathrm{N}(3)-\mathrm{C}(4)$ torsion angle.

An analysis of the atomic charges in molecules under study reveals (Table 3) a considerable increase in the negative charge of the oxygen atoms due to the interaction with water molecules. This result also agrees well with the assumed possibility of some contribution of resonance structure $\mathbf{B}$ into 
the total geometry of the nucleobases. However, the charges of the other atoms vary insignificantly due to the hydration.

\section{Conclusion}

Investigation of the molecular geometry of the complexes of uracil and thymine with 11 water molecules reveal the details of the interactions between the bases and solvent. The presence of a methyl group in thymine results in significant deformation of the hydrated shell.

Interaction with water molecules causes deformation of the intramolecular geometry of the nucleobases which can be described by assuming the contribution of a zwitter-ionic resonance form into the total structure of the bases. However, the predicted deformations of the nucleobases are much smaller compared to hydrated cytosine [21].

An analysis of the topological characteristics of electron density distribution in the complexes under study using a wavefunction obtained at the B3LYP/6-31G(d) level of theory reveals the presence of weak C-H...O hydrogen bonds between the hydrophobic part of the nucleobases and water.

Acknowledgment: This work was facilitated in part by the NSF-Grant No. $9805465 \& 9706268$ and by the Office of Naval Research, Grant No. N00014-98-1-0592 and by NIH Grant No. G1 2RR13459-21.

\section{References and Notes}

1. Franklin, R. E.; Gosling, R. G. Nature 1953, 171, 740.

2. Wolf, B.; Hanlon, S. Biochemistry 1975, 14, 1661.

3. Brandes, R.; Rupprecht, A.; Kearns, D. R.; J. Biophys. 1989, 56, 683.

4. Kennard, O.; Hunter, W. N. Angew. Chem., Int. Ed. Engl. 1991, 30, 1254.

5. Saenger, W. Principles of Nucleic Acid Structure; Springer-Verlag: New York, 1988

6. Poltev, V. I.; Teplukhin, A. V.; Malenkov, G. G. Int. J. Quantum. Chem. 1992, 42, 1499.

7. Sagarik, K.; Corongiu, G.; Clementi, E. J. Mol. Struct. (Theochem) 1991, 235, 355.

8. (a) Miskiewicz, K.; Osman, R.; Weinstein, H. J. Am. Chem. Soc. 1993, 115, 1527; (b) Cramer, C. J.; Truhlar, D. G. Chem. Rev. 1999, 99, 2161.

9. Orozco, M.; Cubero, E.; Barril, X.; Colominas, C.; Luque, F. J. In Computational Molecular Biology; Leszczynski, J., Ed.; Elsevier: Amsterdam, 1999, p 119.

10. Gorb, L.; Leszczynski, J. In Computational Molecular Biology; Leszczynski, J., Ed.; Elsevier: Amsterdam, 1999, p.167.

11. Cramer, C. J.; Truhlar, D. G. Chem. Rev. 1999, 99, 2161.

12. Florian, J.; Sponer, J.; Warshel, A. J. Phys. Chem. 1999, 103, 884.

13. Arora, N.; Jayaram, B. J. Phys. Chem. B 1998, 102, 6139.

14. Broo, A.; Holmen, A. J. Phys. Chem. A 1997, 101, 3589. 
15. van Mourik, T.; Price, S. L.; Clary, D. C. J. Phys. Chem. A 1999, 103, 1611.

16. Aleman, C. Chem. Phys. Lett. 1999, 302, 461.

17. Gorb, L.; Leszczynski, J. Int. J. Quantum. Chem. 1998, 70, 855.

18. Gorb, L.; Leszczynski, J. J. Am. Chem. Soc. 1998, 112, 5024.

19. Gorb, L.; Leszczynski, J. Int. J. Quantum. Chem. 1997, 68, 759.

20. Gu, J.; Leszczynski, J. J. Phys. Chem. A 1999, 103, 2744.

21. Shishkin, O. V.; Gorb, L.; Leszczynski, J. Submitted for publication.

22. Chahinian, M.; Seba, H. B.; Ancian, B.; Chem. Phys. Lett. 1998, 285, 337.

23. Aamouche, A.; Berthier, G.; Cadioli, B.; Gallinella, E.; Ghomi, M. J. Mol. Struct. 1998, 426, 307.

24. Pullman, A. In Quantum Theory of Chemical Reactions; Daudel, R., Ed.; Amsterdam, 1980; Vol. 11.

25. Becke, A. D. J. Chem. Phys. 1993, 98, 5648.

26. Lee, C.; Yang, W.; Parr, R. G. Phys. Rev. B 1988, 37, 785.

27. Miehlich, B.; Savin, A.; Stoll, H.; Preuss, H. Chem. Phys. Lett. 1989, 157, 200.

28. Pudzianowski, A. T. J. Phys. Chem. 1996, 100, 4781.

29. Topol, I. A.; Burt, S. K.; Rasin, A. A. Chem. Phys. Lett. 1995, 47, 112.

30. Gorb, L.; Korkin, A.; Leszczynski, J. J. Mol. Struct. (Theochem) 1998, 454, 217.

31. Reed, A. E.; Curtiss, L. A.; Weinhold, F. Chem. Rev. 1988, 88, 899.

32. Bader, R. W. F. Atoms in Molecules: A Quantum Theory; Oxford University Press: Oxford, 1990.

33. Frisch, M. J.; Trucks, G. W.; Head-Gordon, M.; Gill, P. M. W.; Wong, M. W.; Foresman, J. B.; Johnson, B. G.; Schlegel, H. B.; Rob, M. A.; Replogle, E. S.; Comperts, R.; Andres, J. L.; Raghavachari, K.; Binkley, J. S.; Gonzales, C.; Martin, R. L.; Fox, D. J.; Defrecs, D. J.; Baker, J.; Stewart, J. J. P.; Pople, J. A. GAUSSIAN 94; Gaussian Inc.: Pittsburgh, 1994.

34. Cleland, W. W.; Kreevoy, M. M. Science 1994, 264.

35. Addalsteinsson, H.; Maulitz, A. H.; Bruice, T. C. J. Am. Chem. Soc. 1996, 118, 7689.

36. Desiraju, G. R. Acc. Chem. Res. 1991, 24, 290.

37. Wahl, M. C.; Sundaralingham, M. Trends Biochem. Sci. 1997, 97, 22.

38. Auffinger, P.; Louise-May, S.; Westhof, E. Faraday Discuss. 1996, 103, 151.

39. Shishkin, O. V. J. Mol. Struct. 1998, 447, 1.

40. Shishkin, O. V.; Gorb, L.; Hobza, P.; Leszczynski, J. Submitted for publication.

Supporting Files: 1. Structure of the complex of uracil with 11 water molecules, i1020017-1.pdb; 2. Structure of the complex of thymine with 11 water molecules, i1020017-2.pdb. Download these pdb files to your local disk and then view them using a suitable 3D structure package.

(C) 2000 by Molecular Diversity Preservation International (MDPI, http://www.mdpi.org/) 